\title{
Nanostructured ZnO Arrays with Self-ZnO Layer Created Using Simple Electrostatic Layer-by-Layer Assembly
}

\author{
PilHo Huh ${ }^{1}$ and Seong-Cheol Kim² \\ ${ }^{1}$ Samsung Electronics Co., Ltd., Solar Energy R\&D Center, San \#24 Nongseo-Dong, Giheung-Gu, Yongin-City, \\ Gyeonggi-Do 446-711, Republic of Korea \\ ${ }^{2}$ Department of Nano, Medical and Polymer Materials, Yeungnam University, 280 Daehak-Ro, Gyeongsan, \\ Gyeongbuk 712-749, Republic of Korea \\ Correspondence should be addressed to Seong-Cheol Kim, sckim07@ynu.ac.kr \\ Received 14 November 2011; Accepted 12 February 2012 \\ Academic Editor: Alejandro Manzano Ramirez
}

Copyright () 2012 P. Huh and S.-C. Kim. This is an open access article distributed under the Creative Commons Attribution License, which permits unrestricted use, distribution, and reproduction in any medium, provided the original work is properly cited.

Formation of unique $\mathrm{ZnO}$ nanoarrays utilizing photodynamic polymer, surface-relief grating structures, and unique electrostatic layer-by-layer assembly as a simple and economical methodology was demonstrated. Atomic force microscope (AFM), scanning electron microscopy (SEM), and energy-dispersive X-ray (EDAX) analysis were employed to characterize elemental composition and morphology of the resulting $\mathrm{ZnO}$ nanostructures with self-ZnO layer. Optical behavior of the final product was studied by UV-vis-NIR absorption and photoluminescence (PL) spectra.

\section{Introduction}

Since the large exciton binding energy of $60 \mathrm{mV}$ and quantum confinement effects [1] of low-dimensional nanostructures, zinc oxide $(\mathrm{ZnO})$ has become an attractive candidate for potential electronic, optoelectronic, electrochemical, and electromechanical devices, such as ultraviolet (UV) lasers, [2] light-emitting diodes (LED), [3] field emission devices, $[4,5]$ solar cells, [6] and piezo-nanogenerators $[7,8]$. With changes in size and shape, unique electrical, mechanical, chemical, and optical properties may be freshly introduced, which are extensively believed to be the result of surface and quantum confinement effects [1]. To further improve its physical properties, substantial efforts have been devoted to develop various methodologies to create uniform and continuous one- (1D) or two-dimensional (2D) $\mathrm{ZnO}$ nanostructures. In an effort to integrate the resulting $\mathrm{ZnO}$ arrays into a more ordered fashion to enhance the performance of the nanodevices, a variety of techniques, including nanolithographic techniques (e.g., electron beam lithography, proximal probe patterning, and X-ray patterning) [9] and several chemical methods (e.g., vapor-solid, vapor-liquidsolid, and solution-solid) [10], have been employed. All these methods are not suitable for large fabrication process due to their exorbitant cost and complicated procedure. In contrast, an unconventional method used in this study may be much easier and economically more favorable, considering it can offer a much higher throughput in practice for solar energy conversion, light emission, and other promising areas. Periodic $1 \mathrm{D}$ and $2 \mathrm{D} \mathrm{ZnO}$ nanostructures that were created simultaneously by self-assembly of the $\mathrm{ZnO}$ layers were prepared easily using the electrostatic layer-by-layer (ELbL) method by spin-coating, surface-relief grating (SRG) on the deposited photodynamic polymer film, and finally simple heat treatment. The alternating depositions of aqueous zinc acetate solution utilizing ELbL and polyanions assembly gave a good opportunity for facile fabrication of novel $1 \mathrm{D}$ and $2 \mathrm{D}$ $\mathrm{ZnO}$ nanostructures with self $\mathrm{ZnO}$ layer within a few hours.

\section{Experimental Procedure}

The indium doped tin oxide- (ITO-) coated glass and quartz substrates were used after cleaning by ultrasonication with isopropanol. A photodynamic polymer, poly orange 3 (PDO3), was synthesized from the diglycidyl ether of 

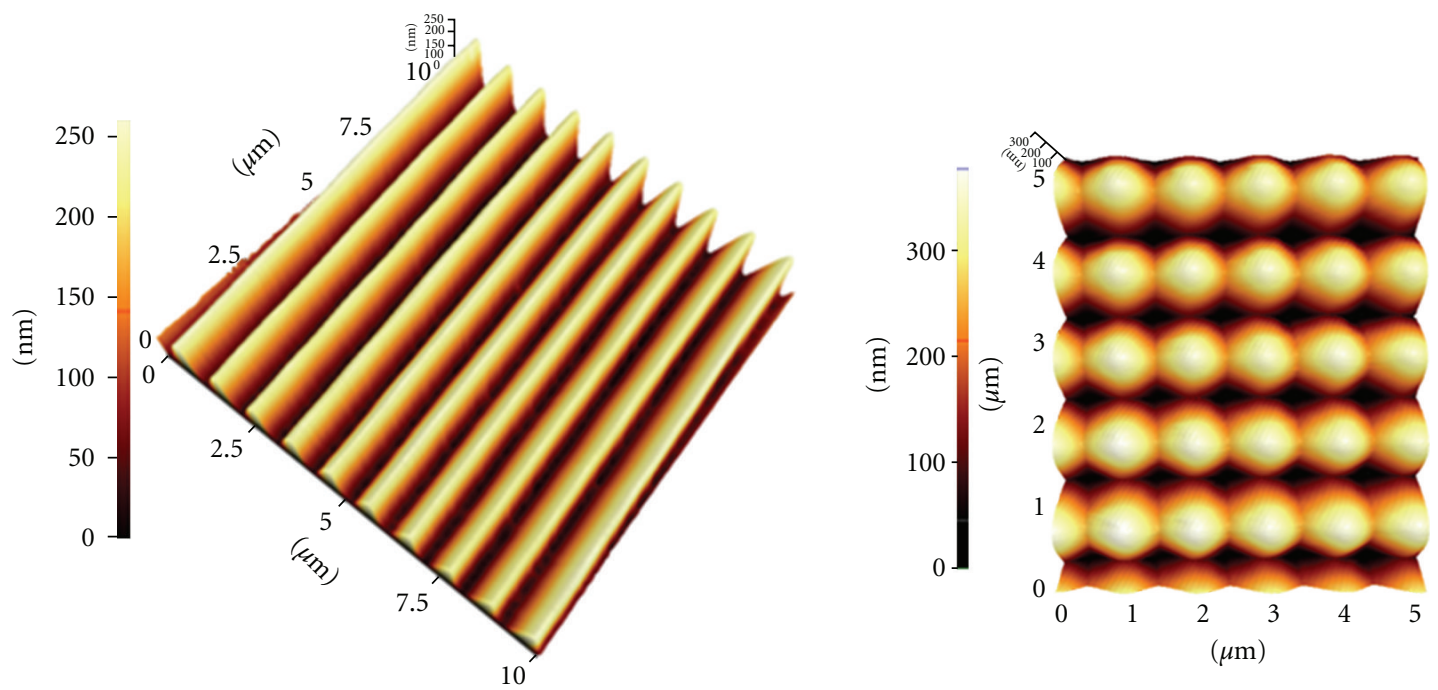

(a)
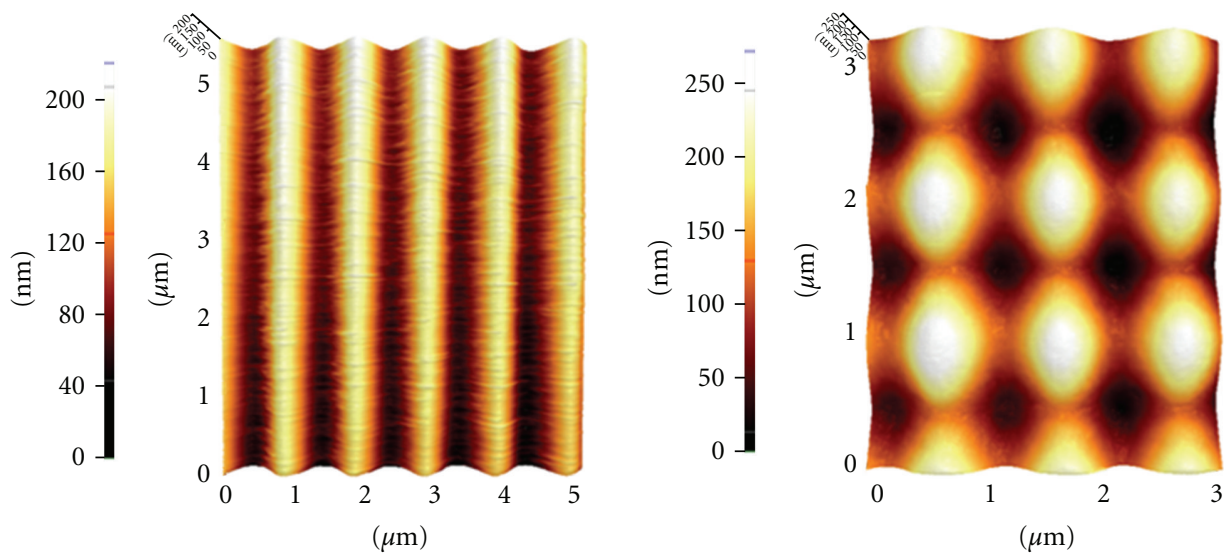

(b)

FIGURE 1: (a) 3D AFM views of submicrostructured 1D and 2D SRGs fabricated by exposing PDO3 to $\mathrm{Ar}^{+}$ion laser interference pattern and (b) 3D views of three bilayers of SPS/zinc acetate assembled in depressions on 1D and 2D SRG polymeric templates.

bisphenol A and disperse orange 3 as reported previously [11, $12] .5 \mathrm{wt} \% \mathrm{PDO} 3$ was dissolved in 1,4-dioxane and filtered through a $0.45 \mu \mathrm{m}$ membrane to obtain a film with uniform thickness. The spin-coated PDO3 films on ITO substrates were then dried in a vacuum oven overnight at $60^{\circ} \mathrm{C} .1 \mathrm{D}$ and 2D Surface-Relief Gratings (SRGs) were formed on the PDO3 films using an interference pattern of an argon ion ${ }^{+}$ laser beam at $514.5 \mathrm{~nm}$ with an intensity of $100 \mathrm{~mW} / \mathrm{cm}^{2}$. $7 \mathrm{wt} \%$ of $\mathrm{Zn} \cdot\left(\mathrm{CH}_{3} \mathrm{COO}\right)_{2} \cdot 2 \mathrm{H}_{2} \mathrm{O}$ purchased from Aldrich was stirred vigorously in $20 \mathrm{~mL}$ of $\mathrm{H}_{2} \mathrm{O}$ for 2 hours to obtain the zinc acetate solution. The concentration of the used poly (4-styrene sulfonate) (SPS) solution was $0.1 \mathrm{wt} \%$ with $\mathrm{pH} 1.0$ for all subsequent polyanion layers. In the assembly process, the SRG templates were quickly modified as sulfonlyl groups by spin-coating the $\mathrm{pH}$ 1.0 SPS solution. $7 \mathrm{wt} \%$ zinc acetate solution was subsequently spin-coated on the SPS surface-modified SRGs. This completed one cycle. A deposition of one-bilayer assembly of the SPS/zinc acetate was progressed in short time without additional drying and rising steps. Thereafter, the process was repeated by alternating the deposition of $\mathrm{pH} 1.0$ SPS solution and $7 \mathrm{wt} \%$ zinc acetate solution until the desired amount of zinc acetate was deposited in the assembly. Three bilayer assembly of the deposited SPS/zinc acetate was heat-treated at $500^{\circ} \mathrm{C}$ for 2 hours to burn off the polymeric template and to create well-defined $\mathrm{ZnO}$ nanostructures with self- $\mathrm{ZnO}$ layer. Scheme 1 illustrates the stepwise procedure used to prepare the nanostructured $\mathrm{ZnO}$ arrays with self-layer.

The samples were characterized by atomic force microscopy (AFM), scanning electron microscope (SEM), and an energy-dispersive X-ray (EDAX) analysis to study their morphologies and elemental compositions. The UVvis-NIR spectrum was recorded at a scan rate of $240 \mathrm{~nm} / \mathrm{min}$. Photoluminescence (PL) spectrum was measured at the exciting wavelength of $345 \mathrm{~nm}$.

\section{Results/Discussion}

Figure 1(a) shows 3D views of (a) 1D and 2D SRGs formed on the photodynamic polymer films. 1D and 2D SRGs were 

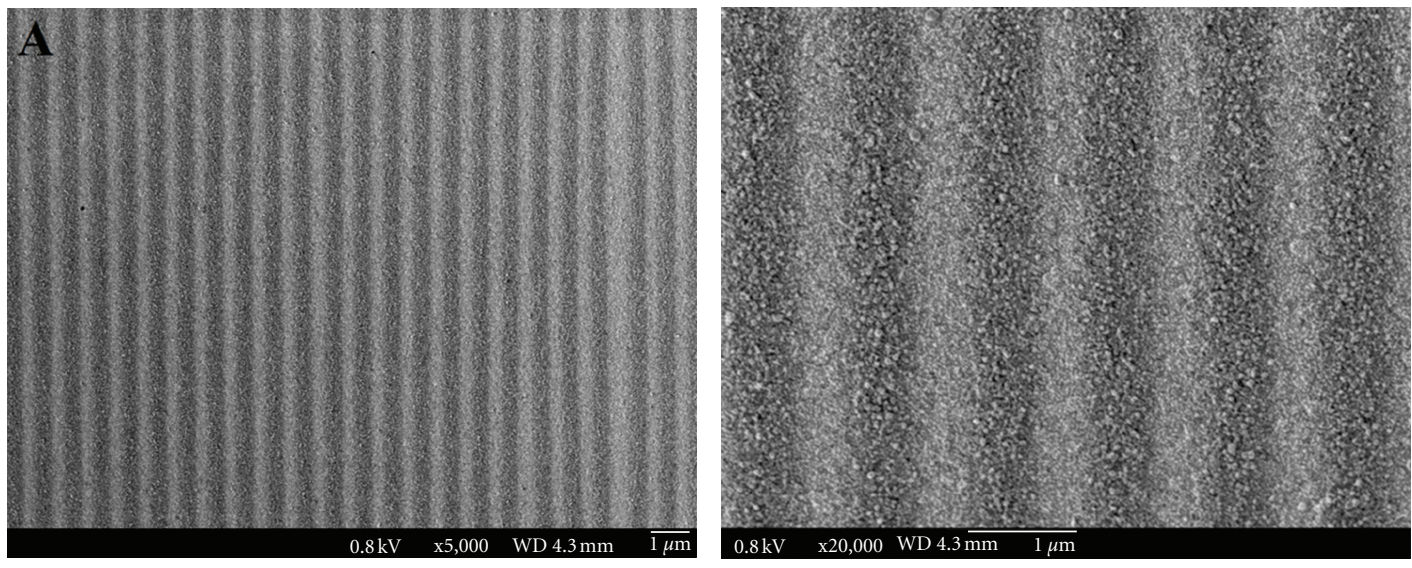

(a)
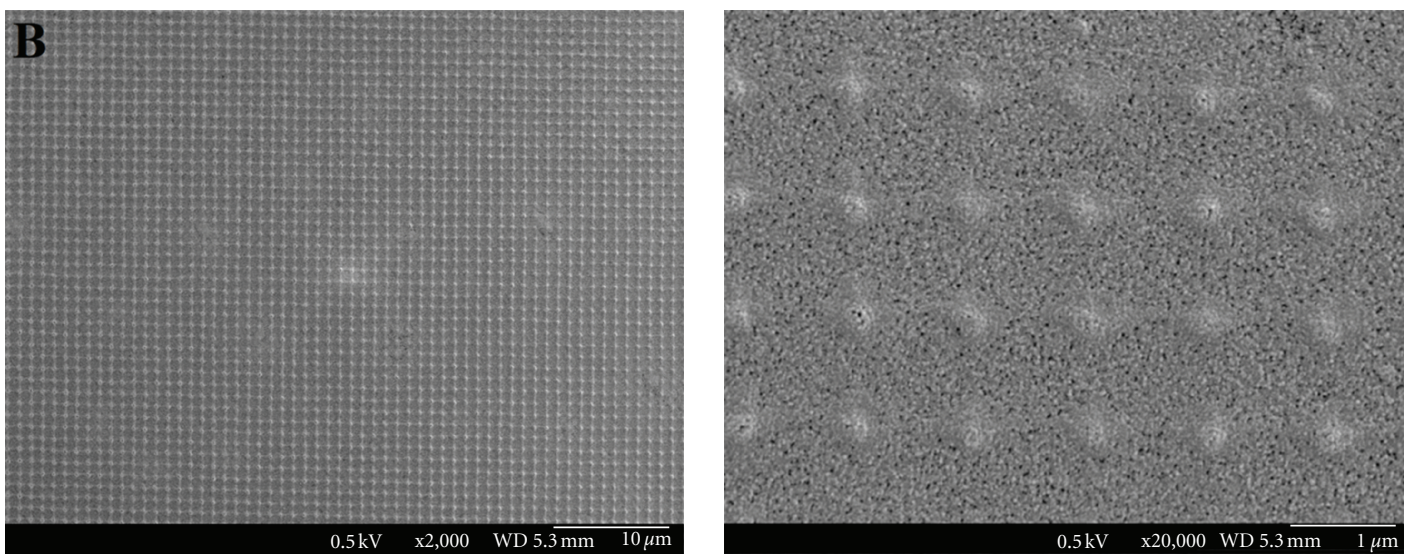

(b)

FIGURE 2: SEM views of nanostructured 1D (a) and 2D (b) ZnO arrays created on self-ZnO layer by simple electrostatic Layer-by-Layer spin-coating technique and pyrolyzing a three-bilayer assembly of SPS/zinc acetate on the individual 1D and 2D SRG templates.

used as polymeric templates to generate well-ordered $\mathrm{ZnO}$ nanostructures. The sinusoidally modulated gratings were used to fabricate a periodic array of $1 \mathrm{D} \mathrm{ZnO}$ lines, while the egg-crate-like SRG structures were used to fabricate periodic arrays of 2D $\mathrm{ZnO}$ dots as shown in Figure 1(a). AFM height profiles of both SRG patterns showed an average modulation amplitude of about 210 and $200 \mathrm{~nm}$, respectively. The periodicities of both gratings are approximately $1 \mu \mathrm{m}$. AFM images in Figure 1(b) show 3D views of an individual threebilayer assembly of SPS/zinc acetate on both SRGs prepared using sequential ELbL by a spin-coating. The thickness of SPS/zinc acetate assembly can be controlled easily by adjusting rpm of spin-coater. Figure 1(b) indicated that the average thickness of SPS/zinc acetates ELbL on 1D SRG for a three-bilayer assembly was decreased by $10 \%$ to about $120 \mathrm{~nm}$ and that for 2D arrays was also reduced nearly by $40 \%$ to about $150 \mathrm{~nm}$, respectively. Each cycle of a SPS/zinc acetate deposition by ELbL spin-coating was successively progressed for a three-bilayer assembly without additional washing and drying. Finally, a three-bilayer assembly of SPS/zinc acetate was dried at room temperature for an hour. Dried assembly was then heated for 2 hours through several steps (room temperature $\rightarrow 100^{\circ} \mathrm{C} \rightarrow 300^{\circ} \mathrm{C} \rightarrow 500^{\circ} \mathrm{C}$ ) to remove the SRG polymeric template and to crystallize Zinc oxide.

Figure 2 summarizes typical SEM images of nanostructured $1 \mathrm{D}$ (a) and $2 \mathrm{D}$ (b) $\mathrm{ZnO}$ arrays created on $\mathrm{ZnO}$ self-layer on the ITO substrate. Well-ordered $1 \mathrm{D}$ and 2D $\mathrm{ZnO}$ arrays were formed as results of the sintering at $500^{\circ} \mathrm{C}$ for 2 hours in air condition as shown in Figure 2. The line and dot arrays created from collection of $\mathrm{ZnO}$ nanoparticles on self-layer show two distinctive shapes such as long sand ridges (a) and sand dunes (b) contrasted with various patterns fabricated by numerous techniques [13-17]. They also exhibit good uniformity and continuity within nanostructured patterns after sintering, although used SRG substrate is a microstructured polymeric template. Unique $\mathrm{ZnO}$ sand ridges and dunes created on self- $\mathrm{ZnO}$ layers may result from the difference of isoelectrical points between SPS polyelectrolyte and zinc acetate layer stacked alternatively. It is quite intriguing to note that zinc acetate layer was stacked selectively and quickly into grooves or hollows without buffer layer, SPS. However, when the buffer layer is present on top of hydrophobic SRG, ZnO-self layer appeared after the sintering process possibly due to adsorption of zinc acetate on the slope. The deposited SPS (or zinc acetate) to the SRG (or 


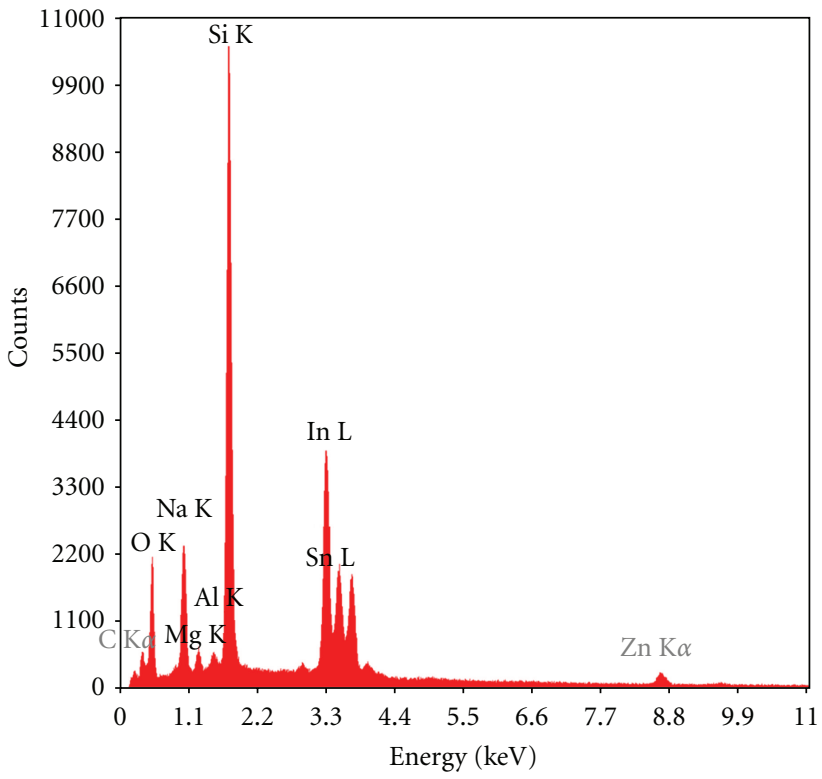

(a)

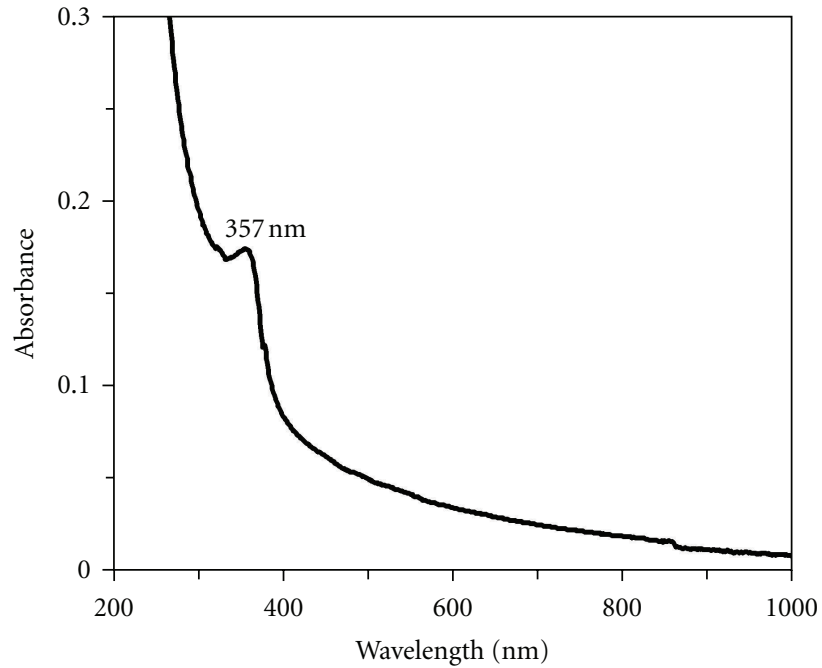

(b)

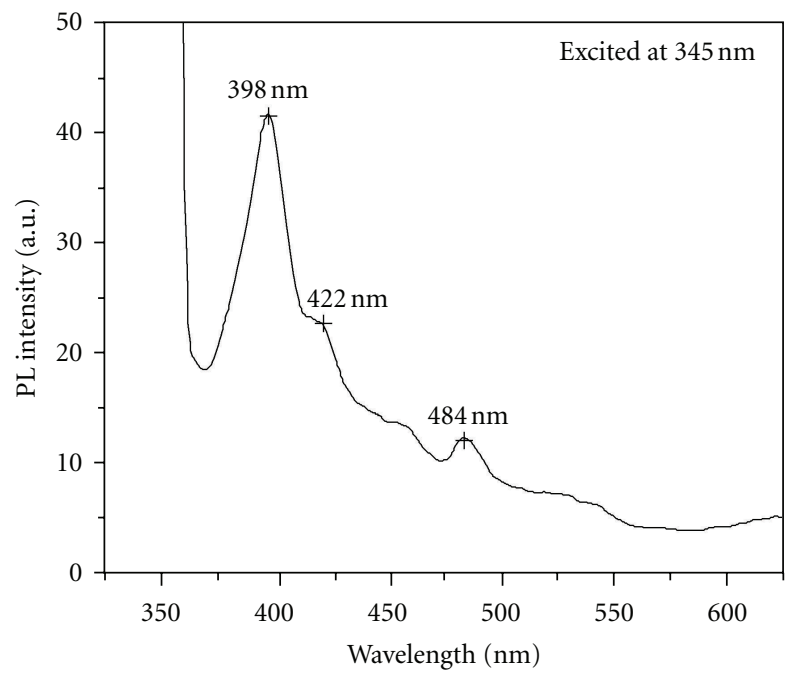

(c)

FIgURE 3: (a) The EDAX spectrum of the 2D ZnO nanostructures shown in Figure 2 for element analysis, (b) UV-vis-NIR and (c) photoluminescence (PL) spectra of nanostructured 2D ZnO arrays with self $\mathrm{ZnO}$ layer created on a quartz substrate; Exciting wavelength for PL is $345 \mathrm{~nm}$.

SPS) may provide more adhesive strength for complexation (or charge interaction) with zinc acetate (or SPS) layer. The resulting $\mathrm{ZnO}$ nanostructures have innumerable porous structures over large area, which can provide a potential advantage for solar cell and sensor applications.

Elemental composition and crystalline structure of $\mathrm{ZnO}$ nanostructures well-patterned on self-layer were determined by energy-dispersive X-ray (EDAX) analysis and Xray diffraction (XRD). The EDAX spectrum of the $\mathrm{ZnO}$ nanopatterns with self-layer in Figure 3(a) clearly shows the $\mathrm{Zn} \mathrm{K} \alpha \mathrm{X}$-ray line at $8.65 \mathrm{keV}$ and $\mathrm{O} \mathrm{K} \alpha \mathrm{X}$-ray line at $0.52 \mathrm{keV}$. A very weak $\mathrm{C} \mathrm{K} \alpha(0.282 \mathrm{keV})$ line compared with that of the non-heat-treated sample is obtained from EDAX spectrum. The crystallinity of the $\mathrm{ZnO}$ nanostructures was confirmed by X-ray diffraction (XRD). In the small sample quantity, three XRD patterns observed at around $2 \theta=31.80^{\circ}, 34.60^{\circ}$, and $36.12^{\circ}$ correspond well to the diffractions from the (100), (002), and (101) planes, respectively $[18,19]$. The results from EDAX and XRD indicated that the produced patterns are composed of crystallized $\mathrm{ZnO}$ nanoparticles and that no significant traces of the SRG polymeric template remained after the sintering process. Other peaks revealed that the existence of $\mathrm{Na}, \mathrm{Mg}, \mathrm{Si}, \mathrm{Sn}$, and $\mathrm{Al}$ come from ITO substrate. UV-vis-NIR spectrum in Figure 3(b) shows the abrupt absorption band or edge characteristic of nanostructured $\mathrm{ZnO}$ arrays with self- $\mathrm{ZnO}$ layer centered at around $357 \mathrm{~nm}$, which is in good corresponding with our previously work [17]. 


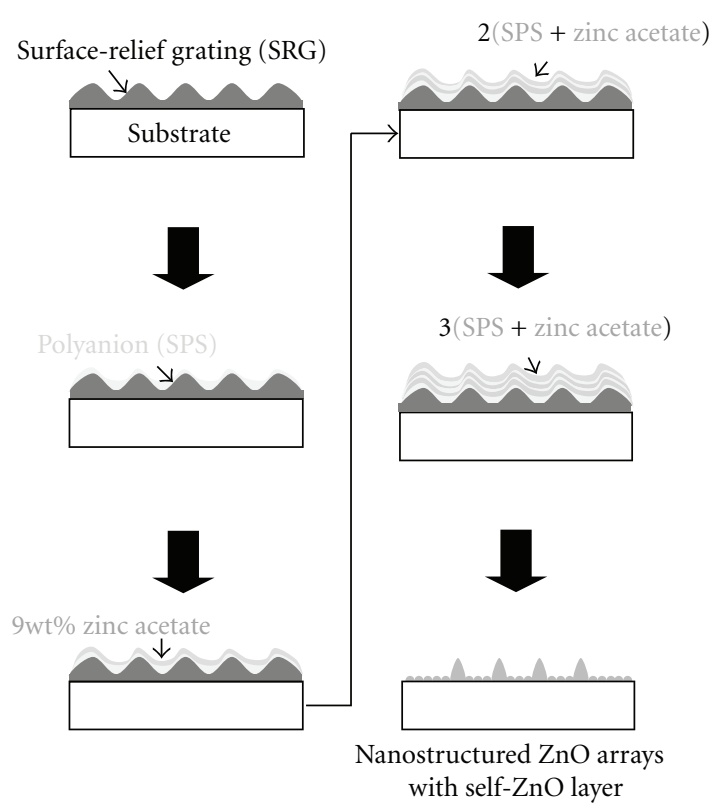

Scheme 1: Schematic procedure for creating nanostructured $\mathrm{ZnO}$ arrays with self-ZnO layer using electrostatic Layer-by-Layer Technique by spin-coating.

The photoluminescence (PL) spectrum of $\mathrm{ZnO}$ nanostructures after sintering at $500^{\circ} \mathrm{C}$ is shown in Figure $3(\mathrm{c})$. The three emission peaks at 398,422 , and $484 \mathrm{~nm}$ in wavelength were obtained from PL spectrum when excited at wavelength of $345 \mathrm{~nm}$. The emission band occurred at around $398 \mathrm{~nm}$ can be assigned to the near band-edge transition, which is, namely, the recombination of free excitons through an exciton-exciton collision process, of wide band gap $\mathrm{ZnO}$ nanoparticles composed of the nanostructured $\mathrm{ZnO}$ arrays [20], while the two emission bands observed at around 422 and $484 \mathrm{~nm}$ result from the radial recombination of a photogenerated hole with an electron that belongs to a singly ionized oxygen vacancy [21] and the defect-induced emission from $\mathrm{ZnO}$ [22-24].

\section{Conclusion}

A simple, cost- and time-effective approach to create periodic nanostructured $\mathrm{ZnO}$ arrays onto self-layer over large areas has been described. The unconventional method was carried out using periodic microstructured polymeric templates, modified ELbL spin-coating technique, and heat-treatment. $\mathrm{ZnO}$ nanoarrays with self-layer are expected to have a wide range of applications such as sensors, energy storages, and solar cells. For instance, various fluorescence dyes may be incorporated in the functionalized $\mathrm{ZnO}$ surface, and $\mathrm{ZnO}$ nanoarrays with self-layer may be also used as a laser pumping due to its attractive optical property. This methodology can be readily applicable for creating nanopatterns with selflayer in other metal oxides, metals, or novel organic materials using common lithographic fabrication methods.

\section{Acknowledgment}

The authors acknowledge the financial support provided by Yeungnam University in the form of research grants in 2009.

\section{References}

[1] D. Bimberg, M. Grundmann, and N. Ledentsov, Quantum Dot Heterostructures, WILEY-VCH, Chichester, UK, 1998.

[2] M. H. Huang, S. Mao, H. Feick et al., "Room-temperature ultraviolet nanowire nanolasers," Science, vol. 292, no. 5523, pp. 1897-1899, 2001.

[3] X. W. Sun, J. Z. Huang, J. X. Wang, and Z. Xu, "A zno nanorod inorganic/organic heterostructure light-emitting diode emitting at $342 \mathrm{~nm}$," Nano Letters, vol. 8, no. 4, pp. 1219-1223, 2008.

[4] X. Bai, E. G. Wang, P. Gao, and Z. L. Wang, "Measuring the work function at a nanobelt tip and at a nanoparticle surface," Nano Letters, vol. 3, no. 8, pp. 1147-1150, 2003.

[5] X. Wang, J. Zhou, C. Lao, J. Song, N. Xu, and Z. L. Wang, "In situ field emission of density-controlled $\mathrm{ZnO}$ nanowire arrays," Advanced Materials, vol. 19, no. 12, pp. 1627-1631, 2007.

[6] M. Law, L. E. Greene, J. C. Johnson, R. Saykally, and P. Yang, "Nanowire dye-sensitized solar cells," Nature Materials, vol. 4, no. 6, pp. 455-459, 2005.

[7] Z. L. Wang and J. Song, "Piezoelectric nanogenerators based on zinc oxide nanowire arrays," Science, vol. 312, no. 5771, pp. 243-246, 2006.

[8] X. Wang, J. Song, J. Liu, and L. W. Zhong, "Direct-current nanogenerator driven by ultrasonic waves," Science, vol. 316, no. 5821, pp. 102-105, 2007.

[9] R. D. Piner, J. Zhu, F. Xu, S. Hong, and C. A. Mirkin, “'Dippen' nanolithography," Science, vol. 283, no. 5402, pp. 661663, 1999.

[10] X. Wang, C. J. Summers, and Z. L. Wang, "Large-scale hexagonal-patterned growth of aligned $\mathrm{ZnO}$ nanorods for nanooptoelectronics and nanosensor arrays," Nano Letters, vol. 4, no. 3, pp. 423-426, 2004.

[11] X. Wang, J. Kumar, S. K. Tripathy, L. Li, J. I. Chen, and S. Marturunkakul, "Epoxy-based nonlinear optical polymers from post azo coupling reaction," Macromolecules, vol. 30, no. 2, pp. 219-225, 1997.

[12] S. S. Kim, C. Chun, J. C. Hong, and D. Y. Kim, "Well-ordered $\mathrm{TiO} 2$ nanostructures fabricated using surface relief gratings on polymer films," Journal of Materials Chemistry, vol. 16, no. 4, pp. 370-375, 2006.

[13] S. K. Donthu, Z. Pan, G. S. Shekhawat, V. P. Dravid, B. Balakrisnan, and S. Tripathy, "Near-field scanning optical microscopy of $\mathrm{ZnO}$ nanopatterns fabricated by micromolding in capillaries," Journal of Applied Physics, vol. 98, no. 2, Article ID 024304, pp. 1-5, 2005.

[14] M. H. Huang, Y. Wu, H. Feick, N. Tran, E. Weber, and P. Yang, "Catalytic growth of zinc oxide nanowires by vapor transport," Advanced Materials, vol. 13, no. 2, pp. 113-116, 2001.

[15] Y. Dai, Y. Zhang, Q. K. Li, and C. W. Nan, "Synthesis and optical properties of tetrapod-like zinc oxide nanorods," Chemical Physics Letters, vol. 358, no. 1-2, pp. 83-86, 2002.

[16] J. Q. Hu and Y. Bando, "Growth and optical properties of single-crystal tubular ZnO whiskers," Applied Physics Letters, vol. 82, no. 9, pp. 1401-1403, 2003. 
[17] P. Huh, F. Yan, A. Li et al., "Simple fabrication of zinc oxide nanostructures," Journal of Materials Chemistry, vol. 18, no. 6, pp. 637-639, 2008.

[18] G. Srinivasan and J. Kumar, "Optical and structural characterisation of zinc oxide thin films prepared by sol-gel process," Crystal Research and Technology, vol. 41, no. 9, pp. 893-896, 2006.

[19] A. Mitra and R. K. Thareja, "Photoluminescence and ultraviolet laser emission from nanocrystalline $\mathrm{ZnO}$ thin films," Journal of Applied Physics, vol. 89, no. 4, pp. 2025-2028, 2001.

[20] Y. C. Kong, D. P. Yu, B. Zhang, W. Fang, and S. Q. Feng, "Ultraviolet-emitting $\mathrm{ZnO}$ nanowires synthesized by a physical vapor deposition approach," Applied Physics Letters, vol. 78, no. 4, pp. 407-409, 2001.

[21] K. Vanheusden, W. L. Warren, C. H. Seager, D. R. Tallant, J. A. Voigt, and B. E. Gnade, "Mechanisms behind green photoluminescence in $\mathrm{ZnO}$ phosphor powders," Journal of Applied Physics, vol. 79, no. 10, pp. 7983-7990, 1996.

[22] T. Aoki, Y. Hatanaka, and D. C. Look, "ZnO diode fabricated by excimer-laser doping," Applied Physics Letters, vol. 76, no. 22, pp. 3257-3258, 2000.

[23] S. B. Zhang, S. H. Wei, and A. Zunger, "Intrinsic n-type versus p-type doping asymmetry and the defect physics of $\mathrm{ZnO}$," Physical Review B, vol. 63, no. 7, Article ID 075205, 7 pages, 2001.

[24] S. Choopun, R. D. Vispute, W. Noch et al., "Oxygen pressuretuned epitaxy and optoelectronic properties of laser-deposited ZnO films on sapphire," Applied Physics Letters, vol. 75, no. 25, pp. 3947-3949, 1999. 

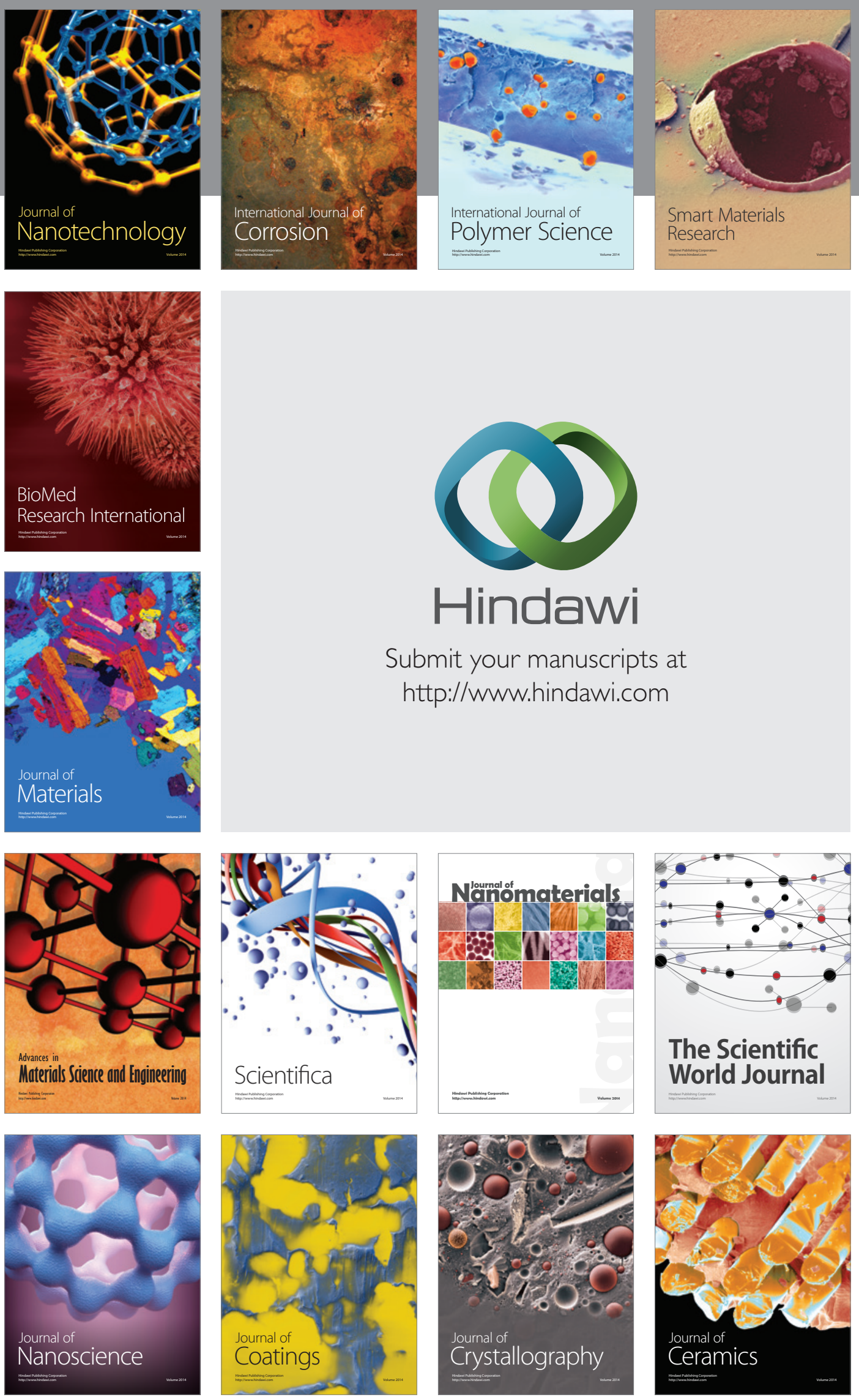

The Scientific World Journal

Submit your manuscripts at

http://www.hindawi.com

\section{World Journal}

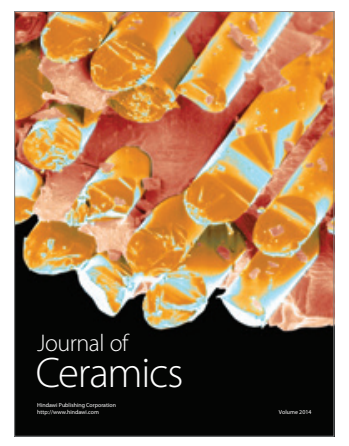

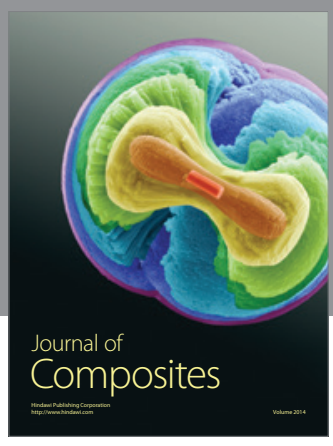
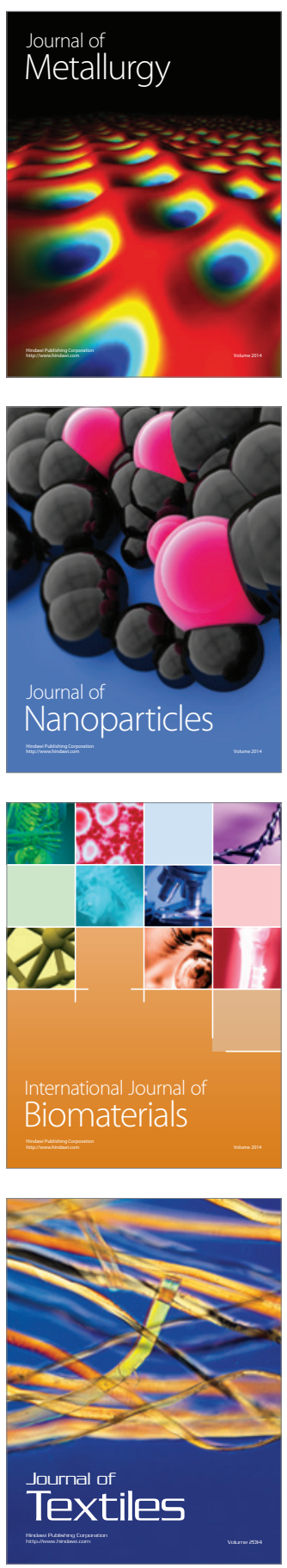